Dialectologia 19 (2017), 109-130.

ISSN: 2013-2247

Received 27 August 2015.

Accepted 19 December 2015.

\title{
PASSIVE CONSTRUCTIONS IN ILAMI KURDISH. A ROLE AND REFERENCE GRAMMAR ACCOUNT
}

\author{
Amir KARIMIPOUR \& Vali REZAI \\ University of Isfahan* \\ am.karimipour@fgn.ui.ac.ir / vali.rezai@fgn.ui.ac.ir
}

\begin{abstract}
As far as obfuscation of the truth is taken into account, passivization seems to be one of the most prominent processes by which the agent of an action may become evasive (by being omitted or demoted to non-obligatory prepositional constituent) in certain contexts. Cross-linguistically, these constructions may not necessarily be formed in an identical fashion, as in some languages such items may be constructed syntactically, morphologically and/ or lexically. In this paper, through employing Role and Reference Grammar framework, we attempt to represent the nature of passive constructions in Ilami, a southern variety of Kurdish language. In pursuit of this goal, we enjoy llami data to represent how passivization could be explained in the RRG [Role and Reference Grammar] framework. Analyzing our Kurdish data, we concluded that llami gains advantage of the main types of passivization strategies. The use of strict morphological, periphrastic and impersonal passives was well-attested, and additionally, it can be said that the two stages of passivization suggested in RRG are done in llami passives.
\end{abstract}

\section{Keywords}

Role and Reference Grammar, Ilami Kurdish, Passive Construction, PSA [Privileged Syntactic Argument]

\footnotetext{
* University of Isfahan, Hezar Jarib Street, Isfahan, Isfahan Province, Iran.
} 


\section{CONSTRUCCIONES PASIVAS EN KURDO ILAMI.}

\section{UNA CONSIDERACIÓN DESDE LA GRAMÁTICA DEL PAPEL Y LA REFERENCIA}

\section{Resumen}

En lo que respecta a la obstrucción de la verdad, la pasivización parece ser uno de los procesos más prominentes por los cuales el agente de una acción puede llegar a ser evasivo (omitiéndose o reduciéndose a un constituyente preposicional no obligatorio) en ciertos contextos. Lingüísticamente, estas construcciones no necesariamente pueden ser formadas de manera idéntica, ya que en algunas lenguas tales aspectos pueden construirse sintácticamente, morfológicamente y/o léxicamente. En este trabajo, a través de la utilización del rol y la gramática de referencia, tratamos de representar la naturaleza de las construcciones pasivas en Ilami, una variedad meridional de la lengua kurda. Para lograr este objetivo, usamos los datos llami para representar cómo la pasivización podría explicarse en el marco RRG [Gramática del Papel y la Referencia]. Al analizar los datos kurdos, concluimos que el llami obtiene ventaja de los principales tipos de estrategias de pasivización. El uso de pasivas morfológicas, perifrásticas e impersonales estrictas ha sido bien atestiguado, y, además, puede decirse que las dos etapas de pasivización sugeridas en la Gramática del Papel y la Referencia se aplican en las pasivas en Ilami.

\section{Palabras clave}

Gramática del Papel y la Referencia, Kurdo Ilami, Construcción pasiva, PSA [Privileged Syntactic Argument]

\section{Introduction}

Passive is a term used in the grammatical analysis of voice, referring to a sentence, clause or verb form where the grammatical subject is typically the recipient or 'goal' of the action denoted by the verb, e.g.

(1) The letter was written by a doctor.

It is contrasted with active, and sometimes with other forms, e.g. 'middle' (as in Greek). A full linguistic statement of the constraints affecting these relationships is a complex matter. In English, for example, there are active sentences that do not have passive counterparts, for example: 
(2) The boy fell, They have a car

And passive sentences which have an unclear active counterpart:

(3) The house was sold.

In addition, there is the problem that the central type of passive construction (using the verb to be, e.g. She was pushed) is closely related to other types of construction (cf. She got pushed, She was interested), and a boundary line is sometimes difficult to establish (Crystal 2008: 353).

Keenan \& Dryer (2007) classifies passives as:

a) Basic passives: what makes them distinct from other passives is (i) no agent phrase (e.g. by Mary) is present, (ii) the main verb in its non-passive form is transitive, and (iii) the main verb expresses an action, taking agent subjects and patient object. Here is an example of this sort:

(4) John was slapped

b) Strict morphological passives: which are constructed through affixation (like infixing in Tagalog and internal vowel change in Arabic and Hebrew). Look at the following example from Sre (Mon-Khmer; Manley (1972)) representing a passive formed by suffixing: ${ }^{1}$

(5) a. Cal pa? mpon wind open door The wind opened the door.

b) Mpon gə-pa? mə cal door PASS-open by wind The door was opened by the wind.

\footnotetext{
${ }^{1}$ Abbreviations used: $A$ = subject of a transitive verb, logical subject; $D E F$ = definite; INDEF = indefinite; $O$ = object of a transitive verb, logical object; OBJ = objective; PASS = passive.
} 
c) Periphrastic passives: which could be constructed according to one of the following ways:

(i) The auxiliary verb is a verb of being or becoming. (Example from Persian.)

(6) a. Ali Ahmad-ra kof-t

Ali Ahmed-OBJ kill- 3SG/PAST

Ali killed Ahmad.

b. Ahmad koft-e Jod

Ahmed kill- OBJ become- PASS- PAST

Ahmad was killed.

(ii) The passive auxiliary is a verb of reception (e.g. get, receive or even eat). (Example from Welsh.)

(7) Cafodd Wyn ei rybuddio gan Ifor

get Wyn his warning by Ifor

Wyn was warned by Ifor.

(iii) The passive auxiliary is a verb of motion (e.g. go, come). (Example from Persian)

(8) a. Ali logat-ra be kar bord.

Ali word-do to work take

Ali used the word.

b. logat be kar raft.

word to work went

The word was used.

(iv) The passive auxiliary is a verb of experiencing (e.g. suffer, touch, even 'experience pleasantly'). (Example from Thai.) 
(9) Mary th'uuk (John) k'oot

Mary touch (John) embrace

Mary was embraced (by John).

(Examples taken from Keenan \& Dryer 2007)

In this study, we aim to represent the way passive constructions are formulated in Ilami Kurdish. By adopting Role and Reference Grammar approach, we attempt to answer the following questions:

1. How passive constructions are made in Ilami Kurdish, morphologically or syntactically?

2. Which passive-related stages (proposed in RRG) are done as far as Ilami examples are taken into consideration?

\section{Review of literature}

Although we have been unable to find a prominent and relevant work in Ilami, there is lots of research done in other varieties, among others, we point to the following cases: Nolan (2005) examines impersonal passive constructions in Irish. He argues that impersonal passive construction in Irish has two forms. The impersonal passive form occurs with all verbs of Irish, across all tenses, whether intransitive or transitive. In the second form, the impersonal passive form is to be found productively with the substantive verb (one of the two verbs of 'to be' in Irish) across all tenses. It does not, however, under any circumstances occur with the copula verb. He then claims that the impersonal passive construction has an indefinite actor at the level of the semantics and that the impersonal passive verb expresses this as a third person indefinite pronoun in the syntax via a synthetic post-verbal suffix rendered on the matrix verb.

Adopting RRG framework, Rezai (2010) assesses passivization in Persian language. He claims that there are two strategies to make passives in that language, one is constructed via a syntactic operation: Objective form of the verb + Jodan called "basic passive" and the other through the $3^{\text {rd }}$ person plural inflexion of the verb with a covert 
subject. Based on RRG criteria for passives, he shows that "transitivity alternation" should be differentiated from regular passivization, as such constructions are not syntactically made; however, they are semantically similar to passives.

Windfuhr (2009) briefly points to the construction of passive in Kurdish. Based on his analysis, passive stems are derived from present stems by -r-e/r-a «*-r-ad): kui-reIkuz-ra- 'be killed'. They are inflected with intransitive subject markers: a-kui-r-e-m 'I am, will be killed'; kui-r-iJ.-.w-im 'I have been killed'; agar bi-kui-r-e-m 'if 1 am killed'; agar bikuz-r-ii- m-ii-y-a 'if 1 had been killed'. In conclusion, the author suggests no other way to construct passive in Kurdish dialects.

Jügel (2009) believes that in a prototypically ergative language, there is no need for a passive because $O$ is the primary actant anyway, and $A$ the secondary. The passive is, so to speak, inherent in the active construction in a prototypically ergative language. Hence an active of an ergative language can be interpreted as an active or as a passive of an accusative language depending on the context.

Leisiö (2006) assesses the passive constructions of Nganasan which is one of the varieties of Uralic language family. She claims that the characteristics of the English passive assigned by Foley and Van Valin (1984: 110-111) hold true for the Nganasan passive, as well. Passivization in this language permits the undergoer to occur as a syntactic pivot. The demoting of the actor follows as a result of the main operation of promotion of the undergoer. Thus, the actor may be either non-specified, or specified and omitted, or explicit-expressed by the lative in morphologically marked passive constructions and by the genitive or/ and a possessive suffix in unoriented-participle constructions. While the unoriented participles and participles of passive verbs retain the aspect characteristics of their base verbs, the passive participles in Nganasan have a resultative meaning. Consequently, the pivot of the passive participle is typically a true patient - it is affected or effected in the result of the action and has more nouny and fewer verbal characteristics than other participles.

Esteban (2012) provides conclusive evidence to decide on the existence or absence of passive in two Native American languages, namely Lakhota and Cheyenne, which exhibit a similar behavior in this respect. In this paper, it is shown that there are two different types of languages with respect to this parameter and that this distinction 
has a bearing on the existence of two different types of passive, whose combination will be exhibited by the English-style passive.

\section{Role and reference grammar}

Introduced by Foley \& Van Valin in 1984, Role and Reference Grammar was inspired by both typological and theoretical concerns. The motivating questions for RRG were:

1- What would a linguistic theory look like if it were based on the analysis of languages with diverse structures, such as Lakhota, Tagalog, Dyirbal and Barai (Papua New Guinea), rather than on the analysis of English?

2- And 'how can the interaction of syntax, semantics and pragmatics in different grammatical systems best be captured and explained?'

These two questions contain both theoretical and descriptive content. On the one hand, they both emphasize the importance of taking account of typologically diverse languages in the formulation of a linguistic theory, and on the other, they indicate that the resulting theory will be one in which semantics and pragmatics play significant roles. (Foley \& Van Valin 1977, 1984, Van Valin 1977, 1981).

RRG maintains that a theory of clause structure should capture all of the universal features of clauses without imposing features on languages in which there is no evidence for them. This assumption rules out, for example, VP as a universal feature of clauses. RRG rejects both grammatical-relations-based representations, such as those in RelG and LFG, and X-bar-type constituent-structure representations, because, it is argued (see Van Valin \& LaPolla 1997), neither type is universally valid. Despite the great diversity of human languages, there are universal features of clause structure: all languages distinguish structurally between predicating and non-predicating elements, on the one hand, and, among the non-predicating elements, between those that are semantically arguments of the predicating element and those that are not. This may be represented schematically as in Figure 1. 


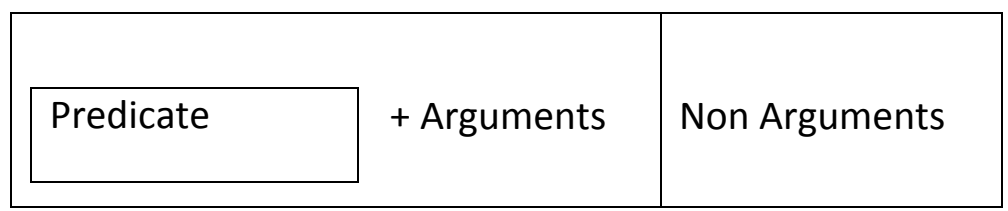

Figure 1. Universal oppositions underlying clause structure

The syntactic unit containing the predicate is termed the nucleus, the unit containing the nucleus plus the arguments of the predicate in the nucleus is called the core, and the unit encompassing the non-arguments (adjuncts) is labeled the periphery. Clauses are thus conceived of as having a layered structure, each layer being motivated semantically.

CLAUSE

CLAUSE

\begin{tabular}{|l|l|}
\hline CORE & \\
\hline NUCLEUS & PERIPHERY \\
\hline & \\
\hline
\end{tabular}

CORE

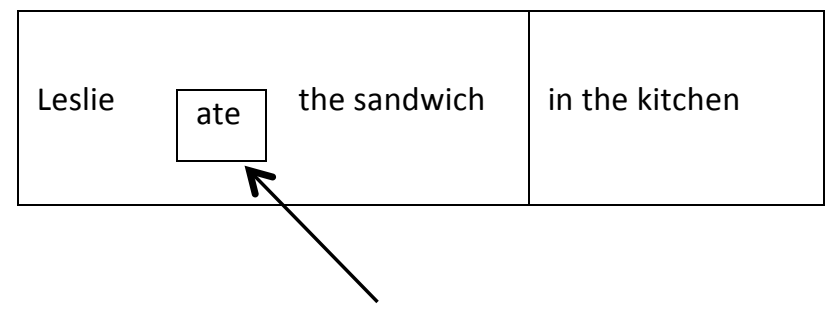

NUCLEUS
PERIPHERY

(Van Valin 2004: 205-206)

\subsection{Organization and representations}

There is a direct mapping between the semantic and syntactic representations of a sentence, unmediated by any kind of abstract syntactic representations; this excludes not only derivational representations as in e.g. the Minimalist Program, but also the use of abstract structures as in LFG. There is only a single syntactic representation for a sentence, and it corresponds to the actual form of the sentence. RRG does not allow any phonologically null elements in the syntax; if there's nothing there, there's nothing there. RRG posits a very concrete syntactic representation, and this constrains the theory significantly; this rules out derivations and therewith movement rules, however 
they are formulated, and also abstract representations like relational networks in Relational Grammar or f-structures in LFG. Many of the descriptive and theoretical devices in theories with abstract syntactic representations are not available in RRG. The organization of RRG is given in Figure 2:

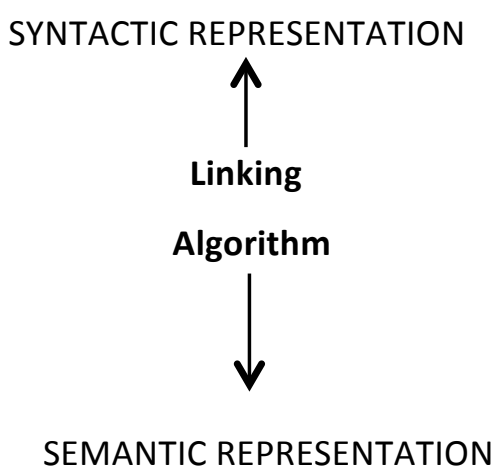

Figure 2. The organization of RRG

The syntactic representation is linked via the linking algorithm to the semantic representation. It consists of a lexical decomposition representation of the meaning of the predicator, along with its arguments. The last component in Figure 2 is labeled 'discourse-pragmatics', and it is parallel to the linking algorithm. What this depicts is the fact that discourse-pragmatics, primarily as realized in information structure, plays a role in the linking between syntax and semantics. Crucially, however, exactly what role it plays can vary across languages, and this variation is the source of important crosslinguistic differences among languages (Van Valin 1992: 3-4).

\subsection{Semantic Roles}

The RRG theory of semantic roles is rather different from that of other theories. There are only two macroroles, actor and undergoer, corresponding to the two primary arguments in a prototypical transitive relation. They are called 'macroroles' because each subsumes a number of specific thematic relations. The first are specific thematic relations, the traditional (since Fillmore 1968 and Gruber 1965) notions of agent, theme, patient, experiencer, etc. The second are generalized semantic roles called 'semantic 
macroroles'; they were introduced in Van Valin (1977) and have no exact analog in other theories, although Jackendoff's 'action tier' and Dowty's proto-roles bear some resemblance.

The role of the subject of an active voice transitive verb and the object of by in a passive construction is actor, and the role of the direct object of an active voice transitive verb and the subject of a passive verb is undergoer. Actor and undergoer are thus generalizations across the thematic relations. The single argument of an intransitive verb is either an actor, as with verbs like run, or an undergoer, as with verbs like die. The relationship between the macroroles and the argument positions in LSs is captured in the actor-undergoer hierarchy in Figure 3.

ACTOR

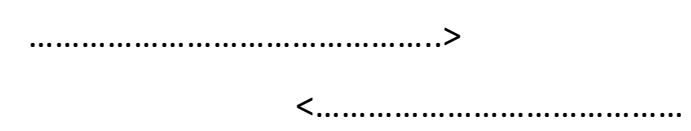

Arg of 1st arg of 1st arg of 2nd arg of Arg of

DO do $\left(x, \ldots \quad \operatorname{pred}^{\prime}(x, y) \quad \operatorname{pred}^{\prime}(x, y) \quad \operatorname{pred}^{\prime}(x)\right.$

[->' = increasing markedness of realization of argument as macrorole]

Figure 3. Actor-undergoer hierarchy

(Van Valin 2005: 13-16)

\subsection{Privileged Syntactic Argument}

RRG has a very different view of grammatical relations from the other theories, because the theory does not attribute cross-linguistic validity to the traditional grammatical relations of subject, direct object and indirect object, and therefore does not employ them as theoretical or analytical constructs. Rather, it adopts a construction specific conception of grammatical relations and postulates only a single one, which is called the 'privileged syntactic argument'. 'Construction specific' means that a privileged argument may be identified for each construction; (Van Valin 2004: 212). So, PSA could be defined as a restricted neutralization of semantic roles and pragmatic functions for syntactic purposes. The other arguments in a clause are characterized as direct or 
oblique core arguments; PSAs may be characterized functionally as controllers or pivots. Have a look at the following illustrations:

a. The tall $\operatorname{man}_{\mathrm{i}}$ hit William and then..........i/ *j ran away.

CONTROLLER

b. William $\mathrm{j}_{\mathrm{j}}$ was hit by the tall man $_{\mathrm{i}}$ and then...... ${ }^{*} \mathrm{i} / \mathrm{j}$ ran away.
PIVOT

\section{CONTROLLER \\ PIVOT}

a. Billi persuaded the tall man $_{i}$

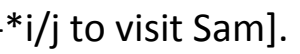

\section{CONTROLLER PIVOT}

b. The tall man $_{j}$ was persuaded by Bill $i$ -*i/j to visit Leslie].

Pivots are canonically the missing argument in a construction, as in the abovementioned examples, while controllers prototypically supply the interpretation for a pivot (Van Valin 2005: 23).

\subsection{Passivization in Role and reference Grammar}

There are usually (but not always) two facets of a passive construction, the occurrence of a marked privileged syntactic argument choice, and the omission of the actor or its appearance as an oblique element in the periphery. Van Valin \& LaPolla (1997) present the universal configuration of basic voice oppositions as follows:

a) PSA modulation voice: permits an argument other than the default argument to function as the privileged syntactic argument.

b) Argument modulation voice: gives non-canonical realization to a macrorole argument.

An important motivation for factoring voice constructions into these two parts is that they occur independently of each other in some languages.

(Van Valin \& LaPolla 1997: 116) 


\section{Methodology}

Examples are taken from llami native speakers who have lived in the region for a long span of time. It might be worth noting that the participants were all above 40 years old with and without formal literacy. In order to analyze our data, we gained advantage of their linguistic intuition throughout the research wherever needed. Needless to say, the final decisions were made based on the authors' analysis.

\section{Ilami Kurdish}

Kurdish as a new western Iranian language has speakers dispersed within broad regions of Iran, from west (Kurdistan, Kermanshah and Ilam) to the east (Khurasan), This language has three main dialect groups: The northern Kurdish dialects are usually given the term Kurmanji spoken in northwestern Iraq (Gunter 2004, xxv-xxvi). The central Kurdish dialects embrace Mukri, which is spoken in Iran, to the south of Lake Urmiya, and Sorani, to the west of Mukri, in the province of Erbil, in Iraq. The southern Kurdish dialect group includes Kermanshahi, Ardalani, Laki (and also Ilami) (Mackenzie 1963; Oranskij 1979: 35-36; Asatrian 2009: 12).

Each of these dialects, moreover, includes infinity of variants so that it is possible to say that every tribe and every valley has its own dialect. This is a phenomenon common to all mountain peoples. In any case it is nothing to be surprised at since, when the national dialects are used, the Arabs of the Maghreb make themselves understood with difficulty by the Iraqis, and the Egyptians do not understand the Lebanese very well. The Kurdish vocabulary is basically Iranian, but it has been influenced by Arabic as has Persian and Turkish, particularly in the department of religion since these peoples are all Muslims for whom the language of the Koran is essential (Bois 1966: 111-112).

Ilami, a less well-documented dialect of the Kurdish language, is widely spoken in Ilam by about 200000 speakers. It shares some features with Kermanshahi in most of its linguistic (e.g. syntactic, morphological and lexical) modules, but shows some 
idiosyncratic characteristics too.

Ilami Kurdish, like many Iranian varieties, is marked as a no- gender/ no- case system in nouns and pronouns. This can be considered as a sharp distinction in comparison with the owning varieties of Kurmanji which have preserved gender and/ or different cases (Bynon 1979). In contrast, llami has pronominal affixes used to construct case relations which are not usually observed in northern dialects of Kurdish.

\section{Data Analysis}

In this section, through presenting llami data, passive constructions will be exemplified. For simplicity's sake, in addition to giving non-literal translations, English grammatical glosses are also given for each example.

\subsection{Privileged Syntactic Argument in Ilami Kurdish}

In an intransitive clause (a clause containing an intransitive verb), the PSA could be either actor or undergoer regardless of the tense of sentence:

(10) ej gæn qwtən-e.

s/he bad cough-3SG PRES

S/he coughs so much.

(11) ej gæn dəqwt-an

s/he bad cough-3SG PAST

S/he coughed so much.

(12) kæf-əm æ xwar

fall-1SG PRES to down

I fall down. 


\author{
(13) kæft-əm æxwar \\ fall- 1SG PAST to down \\ I fell down.
}

Examples (10) and (11) depict contexts in which the syntactic agreement (person and number) is held between the subjects (as actors) and verbs of the sentences; however, in the next two examples, (12) and (13), the agreement is held between the subjects (as undergoers) and the verbs. Based on this fact, it can be said that in llami Kurdish, the syntactic agreement is a subject- verb agreement type and additionally the default PSA is the actor of the sentence.

\title{
6.2 Strict Morphological Passivization
}

In order to make passive sentences, sometimes llami speakers use a specific construction. Have a look at the following examples:
a. ej kwəl-ə had̋̋æt-el-æ Jur-t.
s/he all-POSS dish-PL-DEF wash-3SG PAST
S/he washed all the dishes.

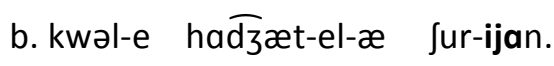

all-POSS dish- PL- DEF wash- PASS PAST

All the dishes were washed.

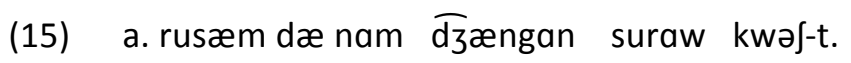

Rusam into battle Suraw kill-3SG PAST

Rusam killed Suraw in a battle.

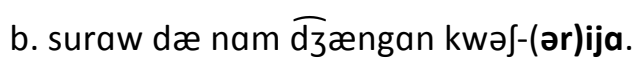

Suraw into battle kill- PASS PAST

Suraw was killed in a battle.

(16)
a. bæt $\overline{\mathrm{t}}-\mathrm{el}-æ \quad$ qæza-(g)æ xwæ-n.
child- PL- DEF food- DEF eatPRES-3PL
The children eat the food. 
b. qæza-(g)æ xwər-e.

food- DEF eat- PASS PRES

The food will be eaten.

a. æli mafin-æ $\int$ Jlpen-e.

Ali car- DEF shatter-3SG PRES

Ali will shatter the car.

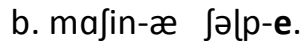

Car- DEF shatter- PASS PRES

The car will be shattered.

Examples (14) through (17) show active and passive counterparts in different semantic contexts. As we can see in all the examples mentioned so far, a given morphological affix (-ija in the past and -e in the present or future tense) is attached to the verb root in order to make the passive form of the verb, hence, they are portmanteau morphemes with the function of time and voice denotation. Actor as the default PSA, which is present in all examples, tends to be omitted in the passive constructions and undergoer (here direct object) adopts the PSA role and appears in the subject position.

If we take example (14) into account, "Jurijan" as the passive form of the verb is in agreement with the marked PSA which is "kwəle hadzætelæ" and it shows that morphologically, there is no longer agreement between the verb and the unmarked PSA (that is "ej" in the active construction) and this comes true regarding other examples too.

Respecting unmarked PSA (actor), it seems that, unlike English, Kurdish passive constructions usually push away any unnecessary element out of the core structure. This is why we can see the previously privileged argument (actor) in none of the passive examples mentioned thus far (even in the periphery). This is not clear why llami passive constructions often drop the actor out of the core structure, however an assumption could be related to the minimization of the actor role which is reflexed through the deletion of this element, or they adhere to the economy principle of the language. We 
should keep in mind that in a few cases, the appearance of unmarked PSA (in the periphery) is optional which is believed to be a non-local pattern entered Ilami Kurdish and could be functionally used in a more or less style:

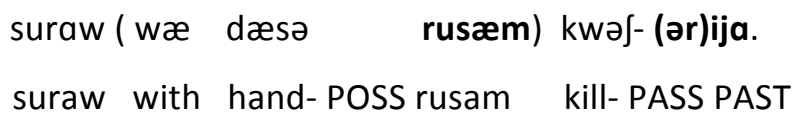

ACTOR

Suraw was killed by Rusam.

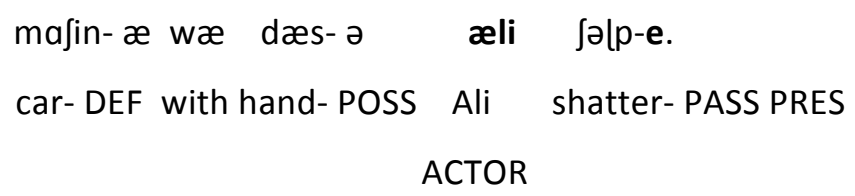

If Ali is the owner of the car, it will be shattered.

Importantly, native speakers make a distinction between the two examples mentioned above. In fact, the first example is a declarative sentence which optionally preserves the unmarked macro role which is "Rusam" in the periphery, while the latter represents a (semantically) conditional sentence meaning "if Ali is the owner of the car, it will be shattered".

The logical structure of the aforementioned example could be so:

$$
\begin{aligned}
& \text { suraw ( wæ dæsə rusæm) kwəJ- (ər)ija. } \\
& \text { Do (Rusæm, [do' (Rusæm, Ø)] CAUSE [BECOME dead' (Suraw)] }
\end{aligned}
$$

It should be hinted that the definite marker $æ$ attached to the undergoer is determinant in the construction of sentence meaning. Should we detach the definite marker $æ$ from the undergoer in example (19), the action done by Ali would be inferred as a habitual action and consequently the passive counterpart seems to be highly unnatural and marked, if not ungrammatical: 


$$
\begin{aligned}
& *^{2} \text { majin Jəlp-e. } \\
& \text { car shatter- PASS PRES } \\
& \text { car will be shattered. }
\end{aligned}
$$

\subsection{Periphrastic passivization}

So far, we represented how morphologically an active sentence could change to a passive one through adding certain morphological suffixes to the verb root. Now let us see if periphrastic passivization also exists in Ilami. By analyzing Kurdish data, we notice that some sentences could change to periphrastic passives and here are some examples of this kind:

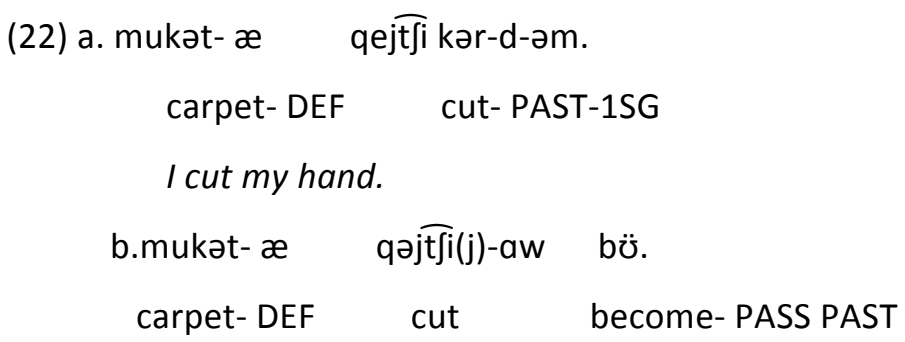

In example (22), am as the actor of the sentence occupies the PSA position and is omitted in the passive sentence, as the PSA role is taken by mukatæ which is now the center of attention. Remind that Keenan \& Dryer (2007) claimed a basic periphrastic passive consists of an auxiliary verb plus a strict morphological function of a transitive verb and one class could occur when "the auxiliary verb (of the sentence) is a verb of being or becoming". Based on this classification, the above illustration could be categorized as a periphrastic passive. It seems that llami Kurdish does not tend to use a purely syntactic operation to construct such sentences; instead a morphosyntactic rule seems to be involved in this operation. This claim is based on the fact that in such examples where " $X$ - büjən"(becoming) is the verb of the periphrastic constructions, there is a morphological suffix -aw attached to the first element of the verb.

\footnotetext{
$2 *$ is used to represent markedness and/ or unacceptability.
} 
Even though it may not be the case in all Kurdish verbs, a morphosyntactic rule could be generalized at least to those verbs owning kardan as the head of the compound verb. In other words, when the verb of the active sentence is " $X+k \partial r d ə n "$, this sentence is prone to be morphosyntactically constructed. Have a look at the following examples:

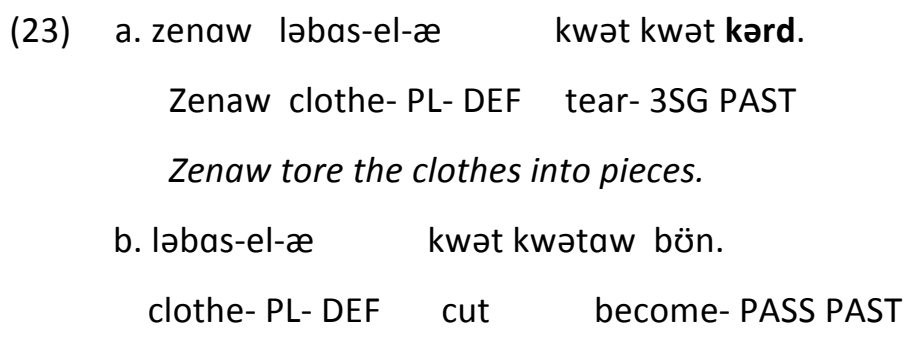

The clothes were/ become torn.

\author{
(24) a. zenaw ləbas- el- æ dər-i. \\ Zenaw clothe- PL- DEF tear- 3SG PAST \\ Zenaw tore the clothes into pieces. \\ b. ləbas-el-æ dər-ija-n. \\ clothe- PL- DEF cut- PASS PAST- 3PL \\ The clothes were/ become torn.
}

It might be worth mentioning that without knowing the active version of the sentences, the passive counterparts seem to be ambiguous, because it is unclear whether an activity has performed upon the undergoer or not. In other words, we are unable to judge whether the verb describes a state or a dynamic action.

\title{
6.4 Impersonal Passive Constructions
}

There are some Kurdish constructions which are specific in some facets. Actually, these sentences are "impersonal passive constructions" as they lack an overt actor in their syntax. This fact is worth taking a look at: 
'təla bər-d-ən.

gold rub- PAST- $2^{/} 3 \mathrm{PL}$

(you/they) stole jewelry.

(26)

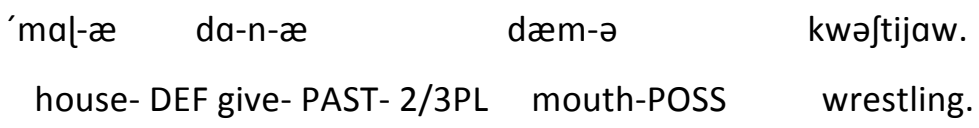

(you/they)made the house messy.

The verbs of the mentioned examples are conjugated in plural $2^{\text {nd }}$ and $3^{\text {rd }}$ person and clearly there is no agreement with the undergoer of the sentence. These constructions are referred to as impersonal passive constructions lacking a definite actor but the passive voice of the sentence is inferable. It is worthwhile mentioning that in Ilami Kurdish, $2^{\text {nd }}$ and $3^{\text {rd }}$ person morphemes are pronounced identically and in this regard, llami is different from other languages in which the verb of impersonal passive constructions takes $2^{\text {nd }}$ and $3^{\text {rd }}$ person morphemes.

As far as accentuation is taken into consideration, it is a must for such constructions to give the undergoer of the sentence the main stress which we have shown it here with an acute stress. Based on this criterion, it can be said that undergoer in such cases is focalised because of conveying new information in the sentence and correspondingly indefinite actor is deleted due to conveying unnecessary information. For example, in example (25) and (26) 'təla' and 'mal' as the undergoers of the sentences have been focalised as the new information of the construction. Additionally, the undergoer may (or may not) take a definite marker, like "æ" for 'mal' and nothing for "təla" respectively.

\section{Concluding remarks}

In this paper, we attempted to show the way passive forms are made in llami Kurdish. Analyzing our data, we found out that passive construction in Ilami is the role of morphology and its interface with syntax. In other words, in the morphology module the 
main type of passive form which is adding an affixal morpheme to the verb root is constructed and many verbs could be passivized in this manner. It was also shown that in the respective construction, actor is usually deleted out of the core construction which is a type of argument modulation. On the other hand, impersonal passive constructions could be made via a syntactic operation which is the deletion of PSA (that is actor), though, the verb inflexion remains intact which is a type of argument modulation. Although PSA role is not handed to the undergoer of the new construction, these forms should be considered as passive forms as the actor of the sentence is prone to drop and is morphologically conflated onto the main verb. Last but not the least, regarding the periphrastic passives, it was noticed that this sort of passive does exist in Ilami Kurdish and they are made through a morphosyntactic operation. Transferring the above findings to RRG framework, we get the following information: Firstly, regarding two phenomena of the universal formulation of basic voice oppositions (PSA and argument modulation), it can be said that in all forms of llami passives including strict morphological passives and periphrastic passives, both stages are done. In fact, in these cases, the actor is omitted or is rarely placed in the periphery and the undergoer becomes the PSA of the sentence. This tells us that in Ilami passives the default PSA is the actor and in specific contexts (passive voice), undergoer is permitted to function as the PSA.

\section{References}

AsATRIAN, G. (2009) "Prolegomena to the Study of the Kurds", Iran and the Caucasus, 13, 1-58.

BYNON, T. (1979) "The ergative construction in Kurdish", Bulletin of the School of Oriental and African Studies, 42(2), 211-224.

BoIs, T. (1966) The Kurds, Beirut, LB: Khayats.

CRYSTAL, D. (2008) $)^{6}$ A Dictionary of Linguistics and Phonetics, Malden, MA: Blackwell Pub.

Esteban, A. C. (2012) "Does There Exist Passive Voice in Lakhota and Cheyenne?", Revista de Lingüística y Lenguas Aplicadas, 7, 77-96. <http://dx.doi.org/10.4995/rlyla.2012.1126> (accessed 11 February 2015). 
Fillmore, C. (1968) "The Case for Case", in E. Bach \& R. Harms (eds.), Universals in Linguistic Theory, New York: Holt, Rinehart \& Winston, 1-88.

Foley, W. \& R. D. Van Valin Jr. (1977) "On the Viability of the Notion of 'Subject'” in Universal Grammar", Proceedings of the Third Annual Meeting of the Berkley Linguistics Society, 3, 293-320.

FOLEY, W. \& R. D. VAN VALIN Jr. (1984) Functional Syntax and Universal Grammar, Cambridge: Cambridge University Press.

GUNTER, M. (2004) Historical Dictionary of the Kurds, Maryland: Scarecrow Press Inc.

GRUBER, J. (1965) Studies in Lexical Relations, Unpublished Ph.D. dissertation, MIT.

JÜGEL, T. (2009) “Ergative Remnants in Sorani Kurdish?”, Orientalia Suecana, LVIII, 142-158.

KeEnAN, E. L. \& M. S. Dryer (2007)2 "Passive in the World's Languages”, in Timothy Shopen (ed.), Clause Structure, Language Typology and Syntactic Description, vol. 1, Cambridge: Cambridge University Press, 325-361.

LEISIÖ, L. (2006) "Passive in Nganasan", in W. Abraham W. \& L. Leisiö (eds.), Passivization and typology: form and function, Amsterdam: John Benjamins, 213- 230.

MACKCENZIE, D. N. (1963) “Kurmandzi, Kurdi, Gurani”, Narody Azii I Afriki, 1, 162-170.

MANLEY, T. (1972) Outline of Sre Structure, Hawaii: Oceanic Linguistics Special Publications.

NolAN, B. (2005) "The Role of Definiteness in the Impersonal Passives of Modern Irish: Towards an RRG Characterization", Paper presented at the 2005 International RRG Conference, Taipei: Academia Sinica.

ORANSKIJ, I. (1979) Iranskie Yazyki v Istorčeskom OsveŠčenii, Moskva: Nauka.

RezAl, V. (2010) "Passive Constructions in Persian: a New Perspective", Research in Linguistics, 2 (1), 19-34.

VAN VAlin Jr., R. D. (1977) Aspects of Lakhota Syntax, Unpublished Ph.D. dissertation, University of California, Berkeley.

VAN VALIN Jr., R. D. (1981) “Grammatical Relations in Ergative Languages”, Studies in Language, 5, 361-94.

VAN Valin Jr., R. D. (2004) An Introduction to Syntax, Cambridge: Cambridge University Press.

VAN VALIN Jr., R. D. (2005) A Summary of Role and Reference Grammar. <http://linguistics.buffalo.edu/research/rrg.html> (accessed 9 February 2015).

VAN VAlin Jr., R. D. (1992) An Overview of Role and Reference Grammar, University of Buffalo, the State University of New York. 
VAN VALIN Jr., R. D., \& R. J. LAPOLLA (1997) Syntax: structure, meaning \& function, Cambridge: Cambridge University Press.

WINDFUHR, G. (2009) The Iranian Languages, New York and London: Routledge. 